\title{
Assessment of Blast Resistant Structures
}

\author{
Arunkumar K, Muthukannan M
}

\begin{abstract}
According to National Crime Record Bureau (NCRB) report, accidents due to Fire has been ranked fifth it's up by three positions from the last year's ranking and accidents due to fire killed more human lives and lead to property loss. Due to explosive accidents, it revealed that loads, for example, the effect of essential sections, and effect of optional parts, and pressure by reflective and blast waves are generated and it collapses the whole structure. To overcome the damages due to fire accidents, strengthening of members, protection to the structure, design the structural member as a more adequate to resist the blast load and design the structure as a blast resistant may be good. In this paper, various structural members due to blast load and the numerical methods to persist the blast load behaviour are reviewed. The behaviours of various type of concrete under blast load were discussed. Based on the review, it may be concluded that to avoid explosive collapse the structural member has to be designed to withstand the blast waves and utilization of adaptable type materials which was light in weight result by decreasing transfer of energy and less strength, less ductile fibres mixed into the concrete will give blast performance to the concrete.
\end{abstract}

Keywords: Blast Resistant Structure, Blast Loading, Field Blast Test, Fibre Reinforced Concrete.

\section{INTRODUCTION}

$\mathrm{P}_{\mathrm{r}}$ increasing number of considerations because of the expanding number of coincidental blasts and bomb blast by anti-humanities. Explosive of blast had an inbuilt capacity of releasing high power in a short time, which results in various reactions and failures to the structure. As per the National Crime Record Bureau (NCRB) report, different un-common reasons for death instances of flame mishaps are recorded. It's also observed that a sum of 1.21 lakh fire accidents of different kinds was occurred in the nation and guaranteeing more than 1.13 lakh lives from 2010-2014. Also, 18,450 instances of fire accidents were accounted for in 2015 which harmed 1,193 and killed 17,700. The fire has been positioned fifth, up by three positions from the most recent year's positioning. At the point when in Fireworks industries, during the assembling procedure of security matches and crackers, explosive accidents happen every now and again, bringing about overwhelming misfortunes of life of human, misfortunes of materials, wounds to labourers and cash. The quantity of fatal and non-deadly mishaps announced that almost 500 people groups were passed on and 10,000 were

Revised Manuscript Received on December 30, 2019.

* Correspondence Author

Arunkumar K*, Department of Civil Engineering, Kalasalingam Academy of Research and Education, Tamil Nadu, India. Email: arunapcivil@gmail.com

Muthukannan M, Department of Civil Engineering, Kalasalingam Academy of Research and Education, Tamil Nadu, India. Email: civilkannan@gmail.com harmed throughout the previous 15 years and breakdown of structure about 300 structures and 10 billion rupees of property loss. A blast in a structure produces four sorts of burdens viz. effect of essential sections, the effect of optional parts, pressure by reflection and blast waves. At the point when the blast accidents are happening, it results in the human live loss and the framework of a building, (Ramasamy and anumohan 2013). The accidents of people's were not handiest by using the unplanned blast, yet in addition, because of the breaking down and fracture of roofs and walls, breaking of home windows, and fractional/entire breakdown of the structures. The livelihoods of peoples are affected by lack of continuity in manufacturing. The structural engineer must take responsibility for decreasing constructing harms related to the accidents of the blast and hold up the response resist of the power. Additionally, it's far essential to control accidents caused by demolishing of fragment rubbish. It could be accomplished in the perfect way of choosing suitable materials for development and structural proportioning. Based on the literature reviewed, the reduction of calculated loads helps to avoid ordinary reflection. And the ways to secure the blast wave were summarized into 4 primary classes including the structure strengthening, resistance and shield to resist blast, (Sekar et al. 2012). An effort has been committed to exerting material behaviours and structure protection to give better protection against blast. This paper present in the compilation of improving the protection of structures against blast through designing blast resistant members such as slabs, columns, beams, walls and panels with alternative materials and additions. The blast resistant structures will be designed as per the codal provisions of Indian standards. Criteria for blast resistant design of structures as per IS 4991 must be taken into consideration while designing.

\section{BLAST LOADING}

\section{A. Slab}

Kuang et al. (2011) examined the RC rectangular slabs exposed to explosive by modelling of unbending inflexible-plastic and they observed the failure of reinforcement and support bending restraints. Failure pattern and dynamic response due to explosives are sketched out. Thiagarajan et al. (2015) studied the reaction and behaviour of HSC and NSC which was reinforced by vanadium alloy and steel under explosive using shock tube. Li et al. (2015) completed the contact blast tests on seven slabs and found that UHPC slabs were superior in explosive objection. The impact of spacing of longitudinal reinforcement and depth of slab against spalling of the UHPC slabs was explored and solutions of accessible methods by empirical models were found. All fragments coming out because of the explosives are gathered and investigated by the sieve. 


\section{Assessment of Blast Resistant Structures}

Wang et al. (2013) found the various severe damages due to spall of RC square slabs, by blast test in close-in environment, and their numerical model was utilized to check the test results. Coughlin et al. (2010) found FRC vehicle barriers blast resistance and damage caused to the specimen, the amount of flying debris was controlled by fibre addition. Foglar et al. (2013) led the blast performance of steel fibre which has a less strength and less ductile, and their blend with polypropylene fibres on the blast test. And also they examined the consolidated impact of varies concrete quality. They conducted the test utilizing $25 \mathrm{~kg}$ TNT charge on slabs of size $0.3 \times 1.5 \times 6 \mathrm{~m}$ which was precasted. Ohtsu et al. (2007) explored the failure response in dynamic of FRC slabs both experimentally and analytically. And a decrease in spall volume failure and average dia were increased the toughness in flexure. Garfield et al. (2011) studied the resistance of normal concrete and FRC with synthetic fibre against explosives by testing square slabs of $1.2 \mathrm{~m}$ size. A steel reinforcement and glass fibre reinforced polymer (GFRP) plates were utilized to retrofit the slab and examined. Wu et al. (2009) seen that retrofitted RC specimen with CFRP plates on both the faces was outperformed well in the air blast test when they conducted the blast test on $2 \mathrm{RC}$ specimens.

Li et al. (2016) examined the static and field blast in the close-in environment on RC slabs with various types of reinforcement. Static tests were completed to acquire the performance with various increments of fibre in the slab. Moreover, to examine the field tests phenomenon based on Multi-Material ALE and Lagrangian calculation, a numerical study was completed. Yusof et al. (2010) displayed results of explosive resistance behaviour of RC specimens which was one-way and simply supported plates with dimensions of $0.6 \times 0.6 \times 0.1 \mathrm{~m}$ by a $1 \mathrm{~kg}$ charge at the standoff of $0.6 \mathrm{~m}$. Maazoun et al. (2017) focused on finding the failure mode and deformation of prestressed hollow core slabs when exposed to the blast. They examined the effects of an explosion by testing four hollow slabs with the constant charge at a different standoff. Mao et al. (2014) examined the performance of UHPFRC slab of size $3.5 \times 1.3 \times 0.1 \mathrm{~m}$ with different fibre content which was simply supported and tested by a charge of $100 \mathrm{~kg}$ of TNT equivalent at 7-12 m distance. It's concluded by the fibres gave additional execution like that given by steel reinforcement.

\section{B. Panels}

Lan et al. (2005) tested the RC composite slab, SFRC slab exposed to explosive loading by sum of 74 specimens using 17 explosives of $8 \& 100 \mathrm{~kg}$ charge weight at $5 \mathrm{~m}$ stand-off distance. They recorded the accelerations, failure modes and overpressure for each type slabs and max displacement by displacement gauge. Wang et al. (2012) studied the underwater blast performance of foam cores and CFRP sheets which were graded density. Pantelides et al. (2014) discovered the performance of FRC wall panel which has a square shape of size $1.2 \mathrm{~m}$ under blast. Dear et al. (2017) tested the air and underwater blast of various polymeric foam and face sheet composite sandwich panels by TNT proportionate charge of $100 \mathrm{~kg}$ at $15 \mathrm{~m}$ stand-off. Furthermore, the performance of sandwich panels which came under graded density against blast has been researched by Gardner.

\section{Beams}

Luccioni et al. (2004) examined the HSC which produced using long steel fibres which were hooked-end as reinforcement. They found the static and explosive behaviour of prism and slab by testing static and blast tests. At last found that, at various strands substance, improvements were observed in the reaction of static flexure. Liu et al. (2018) experimentally and analytically researched the steel RC beam's blast performance by applying blast loading using live explosives for 10 numbers of beams. They evaluated the time histories of pressure reflected, different levels of damage modes and the displacement based on time for the damaged beams.

\section{Walls}

Liang et al. (2017) analyzed the deformation of the wall by numerical models and real time resistance against explosive of the wall by explosive testing. Also, they examined the impact of a few design parameters and found a correct model to less the displacement and improve the capacity of energy absorption. Tai et al. (2011) analyzed the dynamic reaction and wave pressure of the RC structure which was exposed to explosive by LS-DYNA software. They also found the factors of impact by numerical model analysis. Davidson et al. (2005) conducted seven explosive tests on an aggregate of twelve masonry walls which was reinforced with polymer. The walls were designed as a reusable for each test. Utilizing pressure gauges, deflection gauges and single-axis accelerometers, they estimated the Pressures, deflections and accelerations. Ohkubo et al. (2008) tested the RC plates which are reinforced with carbon sheet under explosion and they noticed that fragmentation was avoided by fibre sheet and increment of fibre results in reduction of damage due to spall.

\section{E. COLUMNS}

Hassan Aoude et al. (2015) utilized shock tube for conducting blast test on UHPFRC columns to find the column's performance against explosives. Li (2014) and Hao (2010) predicted the spall of concrete on column by creating 3D numerical models under explosives. Amr A. Nassr (2013) analysed the performance of steel beam under explosives at a constant charge and standoff. Wu et al. (2009) developed the concrete spall composite steel-concrete column model by numerical under explosive load and explored the connection between load capacity parameter. Alicia Echevarria (2015) did an exploratory examination on FRC polymer tube bridge column which was concrete filled under explosive load.

\section{EXPERIMENTAL FIELD BLAST TEST SETUP}

Thiagarajan et al (2015) generated the real high explosives to create air blast pressure by utilized the Blast Load Simulator (BLS) which was appeared in fig 1. It comprises of vessels such as pressure driver, target, and expansion cone, transition rings. At the target vessel front end the specimen was connected by frame which was made of steel. A $9000 \mathrm{~kg}$ TNT was generated by the BLS utilized by the pressure vessel. To keep the vessel in position steel frame of 2 numbers was fixed and to maintain the steel as a pad for bearing compression, cardboard of $6.35 \mathrm{~mm}$ thick was set between the slab base and floor. 
To create one way slab, the supporting of slab was not done in direction of lateral. The measurement was taken on deflection of mid-span, pressure reflected against blast.
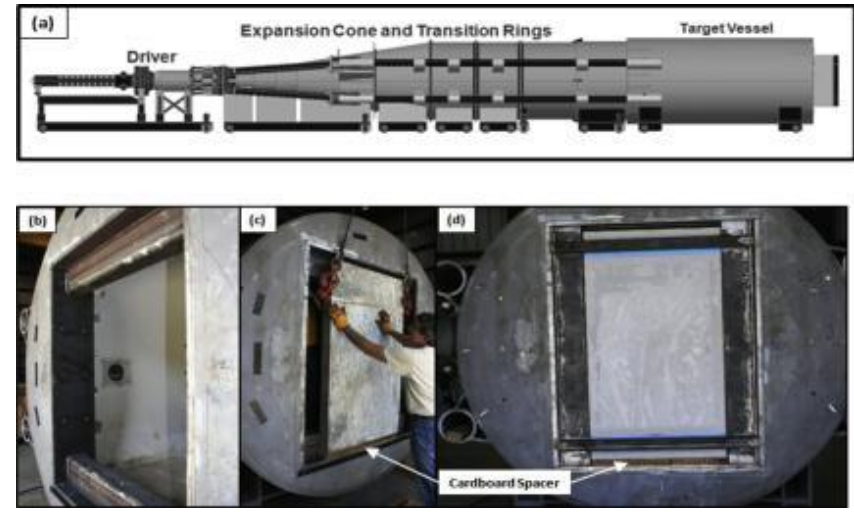

Fig. 1. Blast test set up of RC slabs, Thiagarajan et al (2015)

Li (2015) et al conducted the field blast test by the appeared system in Fig. 2 which has frame of size $5 \times 3.7 \mathrm{~m}$ made by GI pipe. To settle the frame links of 4 were linked from the concrete to frame's upper point and base was connected to the ground by bolt. To resist the damage of frame, in the concrete longitudinal axis supports were created by 2 members of vertical in direction. From the predefined height over the slab by a string, charge of explosive was released. The reflective air pressure was recorded by pressure sensor.

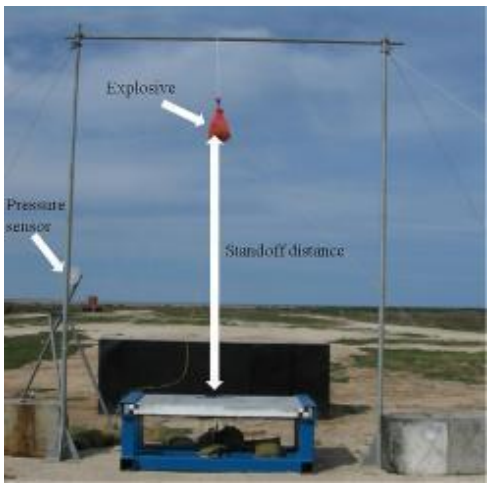

Fig. 2. Reinforced UHPC Slab under field explosive, Li et al (2015)

Foglar et al. (2013) directed investigation based on the design as appeared by Fig. 3. To omit the pressure rebound, the slab was set below one meter depth under the ground by channel of five meters long. Explosive charge of $25 \mathrm{~kg}$ TNT charges was set in the middle slab by steel chair. A speedy camera which has a capacity of taking 15000 frame rates per second was utilized to record the behaviour of slab and lightning of explosives. A mirror which was angled to note down the spall of slab was set below the specimen. The fire extrusions are counteracted by a frame which was timber material. Both sides of concrete were covered by cover towards the view of camera.

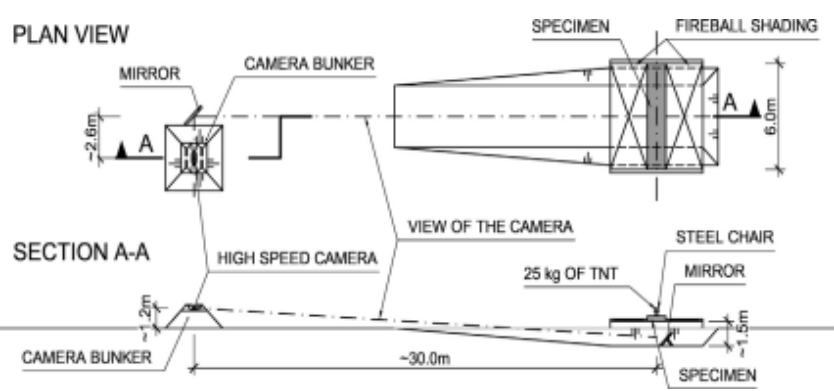

Fig. 3. FRC Bridge blast test set up, Foglar et al. (2013)

Li et al. (2016) conducted the blast test by fixing the slab using bolt (Fig.4) in steel cleat with the help of a crane. To explore the study of slab reinforced with FRP laminates on explosive resistance behaviour, boundary condition as simply supported was generated for all out seven shots were done. The damage levels are found by testing the normal reinforced slab using $0.1 \& 1 \mathrm{~kg}$ explosives which were cylindrical and hollow in shapes.

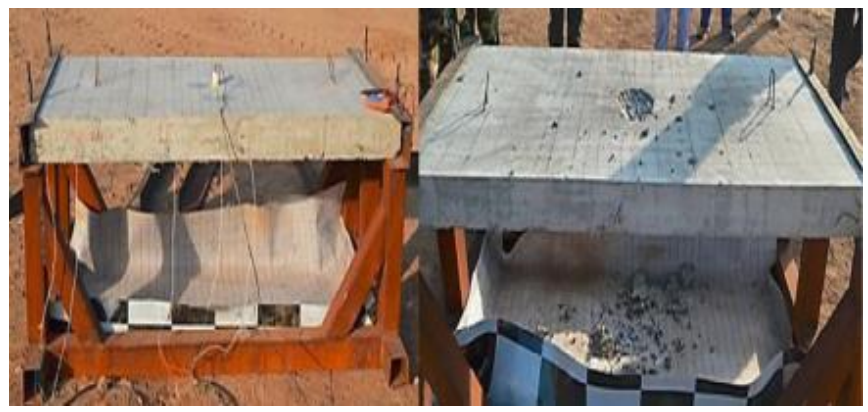

Fig. 4. NRC slabs exploded to field test, Li et al (2016)

Li et al. (2017) tried utilizing TNT explosives in the close-in explosion for test the slab which is settled by bolts clamping system appeared in Fig 5. The test was performed on SFRC and SWM-SF slabs by cylindrical explosive charged of $12 \mathrm{~kg}$ TNT and on NSC slab by $8 \mathrm{~kg}$ TNT, at standoff distances of $0.655,0.655$ and $0.75 \mathrm{~m}$. An LVDT was used to measure the deflection by fixing it on the slab surface. And furthermore, Compression Test, Four Point bending Test and Static flexural behaviour test were also performed. Using LVDT, the beam's mid-span deflection was estimated.

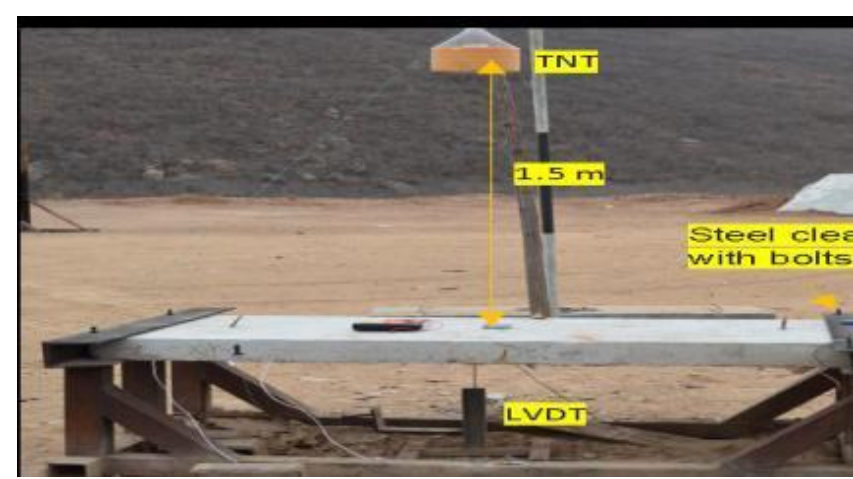

Fig. 5. Steel wire mesh RC slab Field Blast test set up, Li et al (2018) 


\section{Assessment of Blast Resistant Structures}

Lan et al. (2005) tested the concrete specimen which was held vertically with the help of bolt at corner by fixing $14 \mathrm{RC}$ supports by 10 dia of 3 rounds of circle (fig 6). To form simply support condition, perimeter of the support was connected by steel rods using weld. For testing the specimens of SFRC, explosive of 8,20 or $30 \mathrm{~kg}$ and for the PSSRC/SASS/SCSS specimens, $100 \mathrm{~kg}$ explosive were fixed at circle centre, height of specimen centre and also at $5 \mathrm{~m}$ standoff.

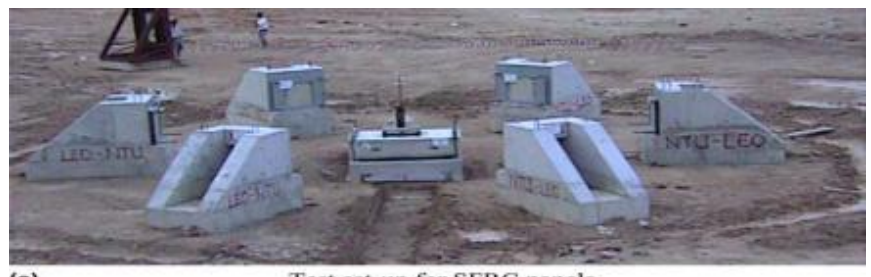

(a)

Test set-up for SFRC panels

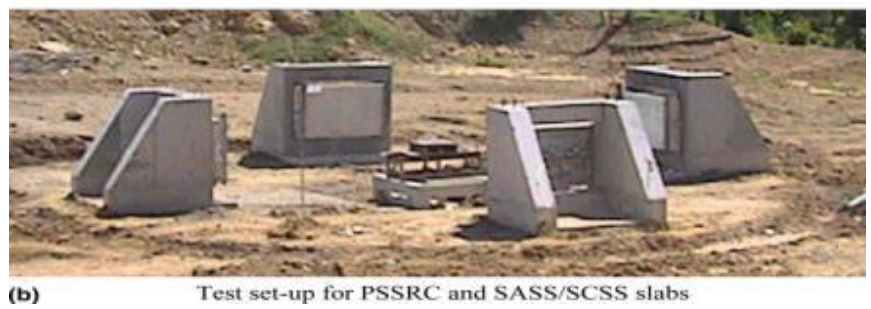

Fig. 6. Composite structural panels field explosive test set up of, Lan et al(2005)

Pantelides et al. (2014) conducted the blast tests utilized by Explosives with a TNT equivalent $6.2-15.6 \mathrm{~kg}$. The test setup was (fig 7) by fixing the explosive at a $1 \mathrm{~m}$ standoff distance by located at centre of the panels which was arranged as a pattern of square. To create the support to specimen, blocks of concrete were developed to fix the specimen in ground. 6 blasts were completed by triggering the Mylar break screen to trig the explosive which was held at the centre height. At centre of mat which was reinforced, the strain measuring gauges were fixed to measure the data acquisition and it has capable of recording 104 data per second.

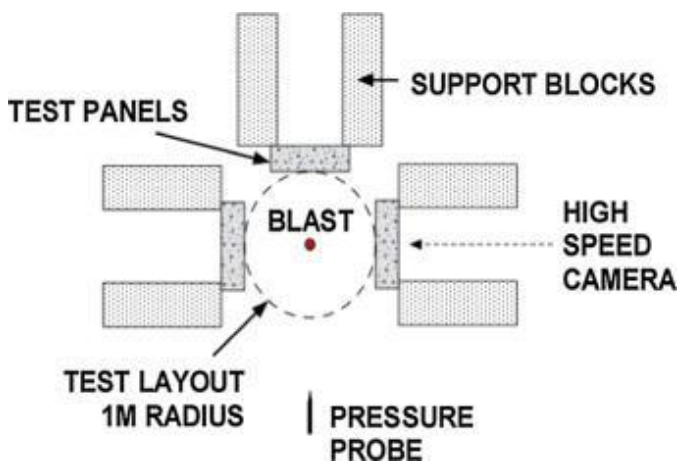

Fig. 7. FRC and RC panel blast test system setup, Pantelides et al (2014)

Dear et al. (2017) conducted the test on panels which was sandwich composite by performing an air, underwater blast tests (Fig 8) by set the explosive of $100 \mathrm{~kg}$ TNT at a distance of $15 \mathrm{~m}$ standoff in the front facing and also damage after blast was analyzed. The test was carried out by fixing the panel using bolts. Record of the events and causes of explosives were captured by the camera which was positioned at $25 \mathrm{~m}$ away. The reviews of cracks in the particle damage after explosive were done by separating the damaged piece into 112 numbers of pieces after blasting. In underwater explosive test was performed by $1 \mathrm{~kg}$ of plastic blast charge fixed at a standoff of $1 \mathrm{~m}$ from centre and at $3.5 \mathrm{~m}$ depth below water and the panels were fixed as the same as air blast setup.

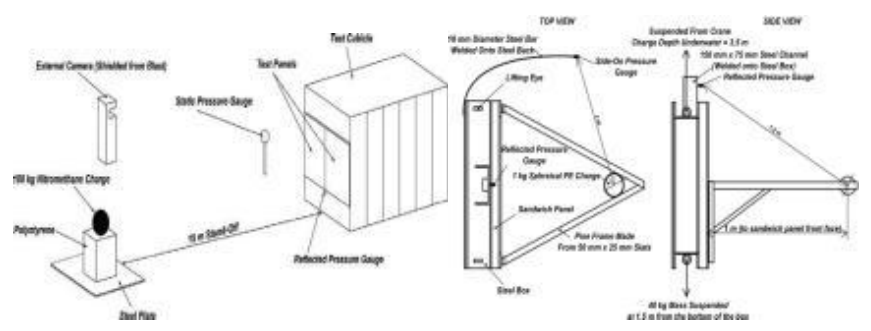

Fig. 8. Air and underwater explosive test setup systems, Dear et al (2017)

Liu et al. (2018) tested all beams using TNT explosive which was fixed at the centre specific height exploded using shock wave propagator. A mass base of concrete was developed to support the beam and at the lower side, it was supported by a groove. The pressure sensor which was known as KD 9-20 was used to record the displacement at centre span of member and to change that displacement to measurable electrical signs (Fig. 9). To record pressure waves due to explosives, DPR Recorder were utilized.

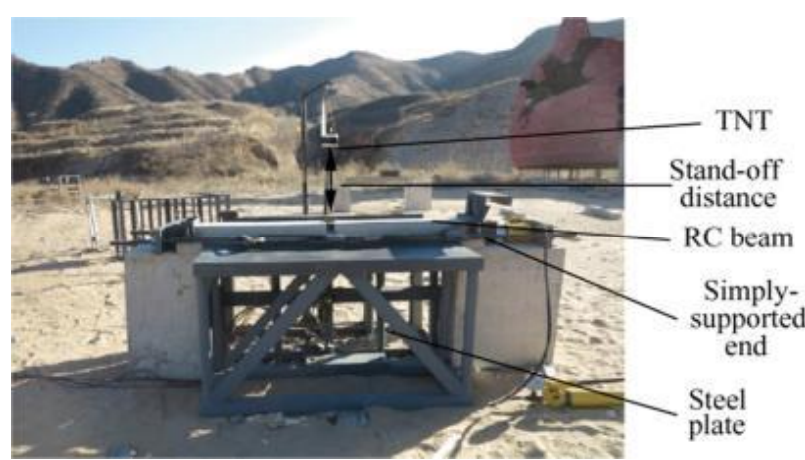

Fig. 9. Field Blast test set up of RC beams and columns, Liu et al (2018)

Liang et al. (2017) set up the experiment by developing an RC room of size $3.4 \mathrm{~m} \times 3.2 \mathrm{~m} \times 2.0 \mathrm{~m}$ with one side masonry wall and steel channel were used to fit the specimen for testing with the help of U clamp (Fig.10). Over the steel channel, a pole was embedded as a vertical divider to hold the explosive charge and charged through the iron wire. To build up the impact parameters explosive TNT was utilized and recorded.

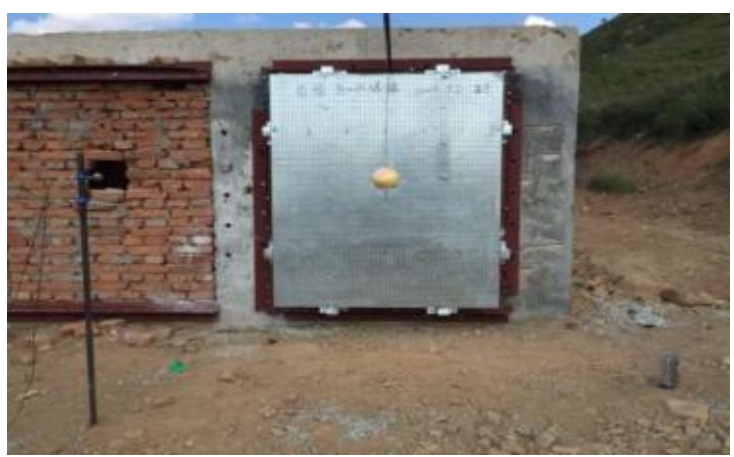

Fig. 10. Field Blast test set up of composite blast-resistant wall, Liang et al (2017) 


\section{DISCUSSION}

According to the analysis of blast test conducted on the various structural elements, the results were discussed below. It has been seen pressure reflection due to blast was lower in the vast majority of the structural materials (steel, solid, glass, and so forth.) compared to materials light in weight (Smith 2006). Transfer of energy to the main structure was less and helps to mitigate the blast pressure was more for the materials which were flexible and light in weight. (Dusenberry 2004). To improve the capacity of mitigation, the wall top should be canopy or overhang (Smith 2006). Kuang et al. (2011) found most powerful tool by numerical model to analyze slab dynamic response. Thiagarajan et al. (2015) concluded that protection level was improved and response level was lessened by producing high strength concrete utilizing materials which have high strength. Li et al. (2015) resulted that the conventional slab was performed low compared to Ultra High Performance concrete slab with $2 \%$ fibre on explosive loads. Li et al. (2016) said that SFRC panels made with $1 \%$ fibre concentration were performed well, and according to size of fibre in crack resistance and spalling resistance, lengthy fibre behaved superior to small size fibre. Garfield et al. (2011) said that Normal concrete with GFRP laminated performed similarly to FRC under explosive loads. Maazoun et al. (2017) finalized that the behaviour of RCHC slab in cracks due to flexure and mid-span deflection was more compared to prestressed concrete hollow slab when utilizing prestressing. Li (2017) et al. found that loading capacity loss of NRC slab was serious when spall and smash of concrete taken place under explosive condition in close environment when compared to UHPC. Lan et al. (2005) showed that according to failure, SFRC panel affected by plastic hinge deformation at the same time slab which was made by normal concrete got failure completely. Davidson et al. (2005) settled that the propagation of shock wave was very effective based on the size of mesh. Damage was occurring at centre of slab when slab had a less reinforcement ratio. Lan et al. (2005) revealed that better blast resistance was achieved by addition $1 \%$ of fibres. Pantelides et al. (2014) dissected the reinforcement spacing was to be in the limit for better panel performance. Compared to other panels, steel reinforced FRC performed better. Dear et al. (2017) exploded that the damage and deflection were less in the sandwich panel. Liu et al. (2018) demonstrated that on back surface, the damages moved from few small cracks to spalling of surface with the decrement of the distance of blast. Likewise, on surface top crushing took place and also expansion took place on $\mathrm{RC}$ beams under the heavy explosive charge. Luccioni B. et al. (2004) said that to overcome the dynamic and static failure, researchers suggested the HSFRC. Liang et al. (2017) revealed that the explosive had a severe impact on deformation and failure. Under explosive, the rupture in petal shape occurred in wall and it tends to deformation at centre. Model was designed to lessen the displacement which was permanently maximum and increase the capacity of absorbing energy. Tai et al. (2011) concluded that introduction of fibres lessens the thickness of cracks, deflection, zone of erosion and spalling and also increase the explosive. Behaviour in static and explosive was increased by addition of long hooked end fibre in HSC.

Li et al. (2014) It is discovered the damage of RC column due to spall was caused by column depth and reinforcement layouts. Expanding depth of the column or using more area of reinforcement provides resistance to damage due to spalling and to predict damage, expressions by analytical was found. Wu et al. (2011) said that improvement of shear and bending of column was by expanding the depth of column and the diagnostic outcomes concluded that the response of column against explosive was not favoured by column height. Hassan Aoude et al. (2015) reasoned that, $2 \%$ to $4 \%$ fibre addition in UHPFRC results in improvement of resistance against explosive and resistance to displacements which was residual and maximum. Fibre properties must be ensured. Barnett (2008) explored that expanding the fibre dose created an expansion in the maximum load resistance. It was discovered that the higher rate of fibre results in toughness and lower rate gave high increment in dynamic affect.

\section{CONCLUSION}

Most of the literature shows that concrete made with fibre had a good blast performance. Less strength and less ductile fibres mixed into the concrete will give blast performance to the concrete. Transfer of energy to the main structure was less and helps to mitigate the blast pressure was more for the materials which were flexible and light in weight. Due to expensive and time consumption of field blast test, new innovative methodologies have to be designed. To overcome the damages of structures, strengthening of members by various techniques and protection or mitigation strategies to the structures can be quite good. From the above reviewed literature, it can be concluded that design the structure as a blast resistant using fibre reinforced concrete or lightweight materials or further advanced energy absorbent materials to resist the collapse of the structure. The blast resistant structures will be designed as per the Indian standards IS 4991.

\section{REFERENCES}

1. A.A. Nassr, A.G. Razaqpur, M.J. Tait, M. Campidelli, S. Foo, Dynamic response of steel columns subjected to blast loading, Journal of structural engineering, (2013).

2. A.A. Nassr, A.G. Razaqpur, M.J. Tait, M. Campidelli, S. Foo, Experimental performance of steel beams under blast loading, Journal of Performance of Constructed Facilities, 26 (2011) 600-619.

3. A.M. Coughlin, E.S. Musselman, A.J. Schokker, D.G. Linzell, Behaviour of portable fibre reinforced concrete vehicle barriers subject to blasts from contact charges, Int. J. Impact Eng 37 (5) (2010) 521-529.

4. A.Maazouna, J.Vantomme, S.Matthys, Damage assessment of hollow core reinforced and prestressed concrete slabs subjected to blast loading, Procedia Engineering 199 (2017) 2476-2481.

5. A.Masood, M. Arif, S. Akhtar, M. Haquie, Performance of ferrocement panels in different environments, Cement and Concrete Research 33 (2003) 555-562.

6. B. Luccioni , F. Isla , R. Codina, D. Ambrosini , R. Zerbino, G. Giaccio, M.C. Torrijos, Effect of Steel Fibres on Static and Blast Response of High Strength Concrete, International Journal of Impact Engineering (2015.)

7. C. Wu, D.J. Oehlers, M. Rebentrost, J. Leach, A.S. Whittaker, Blast testing of ultra-high performance fibre and FRP-retrofitted concrete slabs, Eng. Struct. 31 (2009) 2060-2069.

8. C.P. Pantelides, T.T. Garfield, W.D. Richins, T.K. Larson, J.E. Blakeley, Reinforced concrete and fibre reinforced concrete panels subjected to blast detonations and post-blast static tests, Engineering Structures 76 (2014) 24-33

9. D. Aoude Hassan, Frederic P,Burrell, Russell P,Saatcioglu, Murat, Behaviour of ultra-high performance fibre reinforced concrete columns under blast loading, International Journal of Impact Engineering, 80 (2015) 185-202 


\section{Assessment of Blast Resistant Structures}

10. Echevarria, A.E. Zaghi, V. Chiarito, R. Christenson, S. Woodson, Experimental comparison of the performance and residual capacity of CFFT and RC bridge columns subjected to blasts, Journal of Bridge Engineering, 21 (2015).

11. Foglar M, Kovar M. Conclusions from experimental testing of blast resistance of FRC and RC bridge decks. Int J Impact Eng 2013; 18-28.

12. G. Thiagarajan, A.V. Kadambi, S. Robert, C.F. Johnson, Experimental and finite element analysis of doubly reinforced concrete slabs subjected to blast loads, Int. J. Impact Eng 75 (2015) 162-173.

13. H. Arora, P.A. Hooper, J.P. Dear, Dynamic response of full-scale sandwich composite structures subject to air-blast loading, Composites Part A: Applied Science and Manufactures. 42 (11) (2011) 1651-1662.

14. Hao H, Stewart M, Li Z-X, et al. (2010a), RC column failure probabilities to blast loads, International Journal of Protective Structures 1(4): 571-591.

15. J. Li, H. Hao, Numerical study of concrete spall damage to blast loads, Int. J. Impact Eng 68 (2014) 41-55.

16. J. Magnusson, Fibre reinforced concrete beams subjected to air blast loading, Int. J. Nordic Concr. Res. 35 (2006) 1-17.

17. J. S. KUANG and H. F. TSOIa, Failure of Blast-Loaded Reinforced Concrete Slabs, Procedia Engineering 14 (2011) 2658-2665

18. James S. Davidson, Jeff W. Fisher, Michael I. Hammons, Jonathan R. Porter, and Robert J. Dinan, Failure Mechanisms of Polymer-Reinforced Concrete Masonry Walls Subjected to Blast, Journal of Structural Engineering, ASCE (2005)

19. John P. Dear, Emily Rolfe, Mark Kelly, Hari Arora, Paul A. Hooper, Blast performance of composite sandwich structures, Procedia Engineering 173 ( 2017 ) $471-478$.

20. Jun Li , Chengqing Wu , Hong Hao, Yu Su, Zhong-Xian Li, A study of concrete slabs with steel wire mesh reinforcement under close-in explosive loads, International Journal of Impact Engineering(2018).

21. Jun Li , Chengqing Wua, Hong Hao, An experimental and numerical study of reinforced ultra-high performance concrete slabs under blast loads, Materials \& Design 82 (2015) 64-76

22. Jun Li, ChengqingWu, Hong Hao, ZhongqiWang, Yu Su, Experimental investigation of ultra-high performance concrete slabs under contact explosions, International Journal of Impact Engineering 93 (2016) $62-75$

23. Li J, Hao H. Numerical study of concrete spall damage to blast loads, Int J Impact Eng 2014;68:41-55.

24. Li J, Wu C and Hao H (2015), An experimental and numerical study of reinforced ultra-high performance concrete slabs under blast loads, Materials \& Design 82: 64-76

25. Luccioni B, Ambrosini R, Danesi R. Analysis of building collapse under blast loads, Eng Struct 2004; 26:63-71.

26. M.A. Yusof, Norazman Ariffin, F.M. Zain, Risby, C.P. Ng, Norma strength steel fibre reinforced concrete subjected to explosive loading, Int. J. Sust. Constr. Eng. Technol. (2010) 127-136.

27. Marek Foglar, Radek Hajek, Martin Kovar, Jiři Štoller Blast performance of RC panels with waste steel fibres, Construction and Building Materials 94 (2015) 536-546

28. N. Gardner, E. Wang, A. Shukla, Performance of functionally graded sandwich composite beams under shock wave loading, Composite Structures. 94 (5) (2012) 1755-1770.

29. Ohkubo K, Beppu M, Ohno T, Satoh K. Experimental study on the effectiveness of fibre sheet reinforcement on the explosive-resistant performance of concrete plates, Int J Impact Eng 2008;35:1702-8.

30. Ohtsu M, Uddin FA, Tong W, Murakami K. Dynamics of spall failure in fibre reinforced concrete due to blasting, Constr Build Mater 2007;21:511-18.

31. S. Barnett, Development of advanced concrete materials for anti-terrorism applications, Struct. Eng. 89 (2008) 28-29.

32. S.N. Ramaswamy and A.M. Arunmohan, Static and Dynamic Analysis of fireworks industrial buildings under impulsive loading, IJREAT International Journal of Research in Engineering \& Advanced Technology, Volume 1, Issue 1, March 2013

33. Sekar. T, S.N. Ramaswamy and NVN. Nampoothiri, Studies on strengthening of brick masonry structures in fireworks industries against Accidental explosions, Asian Journal of Civil Engineering, Vol.13, No.6, December 2012, 743-752.

34. Shengrui Lan, Tat-Seng Lok , Leonard Heng Composite structural panels subjected to explosive loading, Construction and Building Materials 19 (2005) 387-395

35. Smith PD and Rose TA (2006) Blast wave propagation in city streets an overview. Progress in Structural Engineering and Materials 8(1): $16-28$.
36. T. Ngo, P. Mendis, T. Krauthammer, Behaviour of ultrahigh-strength prestressed concrete panels subjected to blast loading, J. Struct. Eng. 133 (2007) 1582- 1590

37. T.T. Garfield, W.D. Richins, T.K. Larson, C.P. Pantelides, J.E. Blakeley, Performance of RC and FRC wall panels reinforced with mild steel and GFRP composites in blast events, Procedia Eng. 10 (2011) 3534-3539. ISSN 1877- 7058

38. W. Wang, D. Zhang, F. Lu, S. Wang, F. Tang, Experimental study and numerical simulation of the damage mode of a square reinforced concrete slab under close-in explosion, Eng. Fail. Anal. 27 (2013) 41-51.

39. Wang Y, Liew JR and Lee SC (2015) Experimental and numerical studies of non-composite Steel-Concrete-Steel sandwich panels under impulsive loading, Materials \& Design 81: 104112.

40. Wu C, Nurwidayati R, Oehlers DJ. Fragmentation from spallation of RC slabs due to air blast loads, Int J Impact Eng 2009; 36: 1371-6.

41. Wu K-C, Li B, Tsai K-C. Residual axial compression capacity of localized blast-damaged RC columns. Int J Impact Eng 2011; 38:29-40.

42. Wu K-C, Li B, Tsai K-C. The effects of explosive mass ratio on residual compressive capacity of contact blast damaged composite columns, J Construction Steel Res 2011; 67:602-12.

43. Xingxing Liang, Zhongqi Wang, Runan Wang, Deformation model and performance optimization research of composite blast resistant wall subjected to blast loading, Journal of Loss Prevention in the Process Industries (2017)

44. Y.S. Tai, T.L. Chu, H.T. Hu, J.Y. Wuc, Dynamic response of a reinforced concrete slab subjected to air blast load, Theoretical and Applied Fracture Mechanics 56 (2011) 140-147

45. Yan Liu, Jun-bo Yan, Feng-lei Huang, Behaviour of reinforced concrete beams and columns subjected to blast loading, Defence Technology (2018)

46. Yufeng Shi, Mark G. Stewart, Damage and Risk Assessment for Reinforced Concrete Wall Panels Subjected to Explosive Blast Loading, International Journal of Impact Engineering (2015).

47. Accident Statistical yearbook of India by Govt of Indiahttp://mospi.nic.in/statistical-year-book-india/2017/207

48. Fire accidents in India so http://www.beyondcarlton.org/7-worst-fire-accidents-india-2018/

49. Fire Accidents

Strategies

https://factly.in/fire-accidents-caused-an-average-of-62-deaths-per-day -in-the-last-5-years/

50. India risk Survey Report 2017 by FICCI http://ficci.in/Sedocument/20416/India-Risk-Survey-2017-Report.pdf

\section{AUTHORS PROFILE}

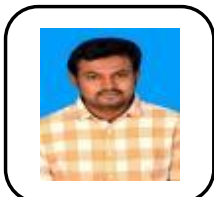

Mr. Arunkumar K is pursuing his $\mathrm{PhD}$ in Department of Civil Engineering from Kalasalingam Academy of Research and Education, Krishnankoil, India. He pursued his Bachelor degree in Civil Engineering from Sengunthar Engineering College, Tiruchengode, affiliated to Anna University, Chennai. Also, he pursued Master of Technology in Structural Engineering from Kalasalingam University, Krishnankoil. His areas of interests are Concrete Technology and Ferrocement Technology.

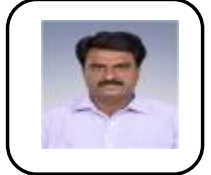

Dr.Muthukannan M completed his Ph.D in Civil Engineering in Anna University, Chennai in the year 2010. He completed Master of Engineering in the field of Transportation Engineering and Management in College of Engineering, Guindy, Chennai in the year 2004. He completed his Bachelor of Engineering under Madurai Kamarajar University in the year 2000. He is presently working as a Professor in Civil Engineering department at Kalasalingam University, Tamilnadu, India. He is guiding for many Ph.D scholars in the field of transporation engineering and computer applications in transportation network using graph theory. $\mathrm{He}$ has published various quality papers in the reputed journals. His main thrust research areas are transportation network design, transport management and travel demand management. 